\title{
An Epidemiologic Study of Dental Caries in Race and Geographic Area
}

\author{
R. A. BAGRAMIAN and A. L. RUSSELL \\ School of Public Health, The University of Michigan, \\ Ann Arbor, Michigan 48104, USA
}

Dental caries experience was determined for white and black high school students in a northern and a southern city of the United States. Expected racial and geographic differences were not found. White and black students showed similar caries experiences, and black students had a higher incidence of caries than reported in earlier studies.

It has been believed that differences in dental caries experience exist between whites and blacks, and between persons living in southern and northern states. Blacks have been reported to have lower caries experience than whites. ${ }^{1}$ Caries experience of blacks in the North is similar to that of whites in some reports,, 3 but in the South, caries experience of whites often has been reported as twice as high as that of blacks. ${ }^{4-7}$

Most previous studies were conducted in one geographic area, which made a comparison of geographic differences in caries experience difficult. A few studies considered more than one geographic area. ${ }^{1,8,9} \mathrm{~A}$ geographic and racial pattern emerged, even though the studies lacked standardization of examining criteria.

Because of the limitations of the studies reported, an investigation was made using the same examiner and identical examining procedures in two different geographic areas to verify the racial and geographic differences presented previously.

\section{Materials and Methods}

High school students were selected for study. Detroit, Michigan, was selected as

Based on a thesis submitted to the School of Public Health, The University of Michigan, in partial fulfillment of the requirements for the PHD degree.

This investigation was supported in part by USPHS Research Training Grant 5 T01 DH 02005 from the National Institutes of Health, Bethesda, Md.

Received for publication June 29, 1970. the northern city and Columbia, South Carolina, was selected as the southern city. The student population sample was restricted to lifetime urban residents with similar environmental conditions, such as socioeconomic status and no previous exposure to fluoridated water, except that both city water supplies were fluoridated approximately one year before the study. Socioeconomic status of school populations was confirmed by consultation with welfare departments, city health departments, census bureaus, and city school systems. Schools located in upper socioeconomic areas of the cities were not included in the survey because of inadequate numbers of representative racial groups.

Dental examinations were conducted in the school buildings, with a portable chair and dental spotlight. No. 23 explorers and no. 5 mouth mirrors were used to detect lesions. Radiographs were not used. Caries experience was expressed in terms of the number of decayed, missing, and filled (DMF) teeth. All examinations were completed by the principal author. Only obvious lesions in which soft dentin could be detected were recorded as carious. An assistant was used to record the findings.

\section{Results}

Subjects for the study were 1,486 white and black high school students in Detroit and Columbia, aged 14 to 17 years. The DMF teeth for each person, and the mean DMF teeth for each group, were tabulated by age, sex, race, and residence. Table 1 illustrates the results. The mean ages ranged from 15.6 to 16.1 years and were considered the same.

To determine whether differences or lack of differences between groups might have been artifacts associated with age distribu- 
TABLE 1

Mean Numbers of DMF Teeth for White and Black Males and Females in Detroit and Columbia, 1968

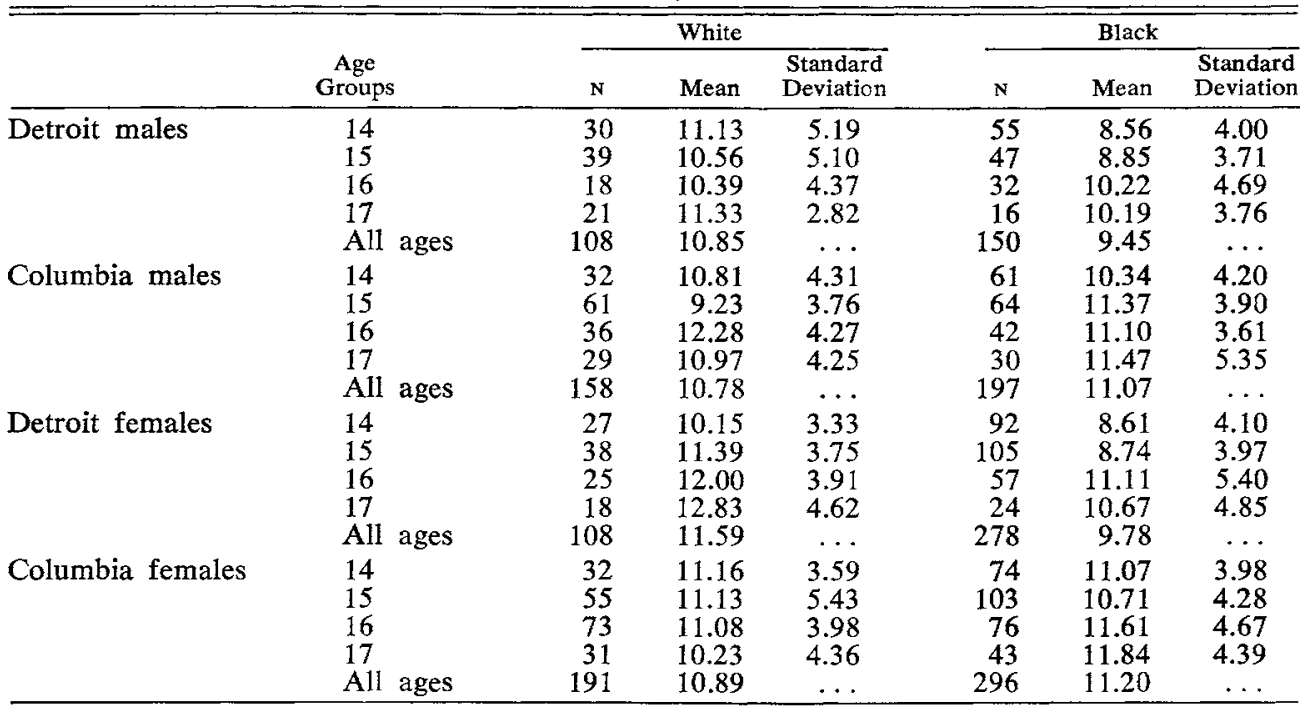

tion, mean numbers of DMF teeth were adjusted to the age distribution of black females in Columbia. This group was chosen for adjustment because it included the largest number of individuals $(\mathrm{N}=296)$. The adjusted values differ little from the crude values (Table 2).

Data were analyzed by a computer to determine significance of caries experience among the variables. In Detroit, significant differences were reported for race and age, with no significant difference between the sexes. The $F$ test value was $16.4403(P<$ 0.005 ) for race, which indicated a higher caries experience for white students than black students. The $F$ test value for ages

TABLE 2

Age Adjustment of DMF TeETH For White and Black, Males and Females in DETROIT AND COLUMBIA

\begin{tabular}{|c|c|c|c|}
\hline & City & $\begin{array}{l}\text { Mean } \\
\text { DMF } \\
\text { Teeth }\end{array}$ & $\begin{array}{c}\text { Adjusted } \\
\text { Mean } \\
\text { DMF } \\
\text { Teeth }\end{array}$ \\
\hline White & Detroit & 10.85 & 10.77 \\
\hline males & Columbia & 10.78 & 10.63 \\
\hline Black & Detroit & 9.45 & 9.32 \\
\hline males & Columbia & 11.07 & 11.06 \\
\hline White & Detroit & 11.59 & 11.45 \\
\hline females & Columbia & 10.89 & 10.99 \\
\hline Black & Detroit & 9.78 & 9.60 \\
\hline females & Columbia & 11.20 & 11.20 \\
\hline
\end{tabular}

Note: Adjusted to age distribution of black females in Columbia.
$(F=4.0116, P<0.01)$ also suggested that the increased caries experience in Detroit students was significant.

The analysis of variance for Columbia did not show significant differences by race, sex, or age, in relation to mean DMF teeth. Table 3 presents the analysis of variance results.

There was a significant difference in the analysis of variance for the total Columbia sample and the total Detroit sample in relation to mean DMF teeth $(F=5.3908$, $P<0.025)$. The mean DMF teeth for Columbia individuals was slightly higher than the mean for Detroit individuals (11.01, as compared to 10.42 ). The mean value of Columbia individuals exceeded the mean value of Detroit individuals by $5.40 \%$. When the data were analyzed graphically (Figs 1,2 ), the differences were insignificant in all instances except in Detroit, where the mean DMF teeth for black females was $23 \%$ less than the mean DMF teeth for white females.

\section{Discussion}

These findings show unexpected trends in caries experience for whites and blacks in South Carolina and Michigan. Little or no difference was found in caries experience between whites and blacks in Columbia, and differences favoring blacks in Detroit 
TABLE 3

ANalysis of Variance of White and Black, Males and Females in Detroit and Columbia for Race, Sex, and Age in Relation to MEAN DMF TEETH

\begin{tabular}{|c|c|c|c|c|c|}
\hline $\begin{array}{l}\text { Source of } \\
\text { Variation }\end{array}$ & $\begin{array}{l}\text { Sum of } \\
\text { Squares }\end{array}$ & $\begin{array}{l}\text { Degrees } \\
\text { of } \\
\text { Freedom }\end{array}$ & $\begin{array}{c}\text { Mean } \\
\text { Square }\end{array}$ & $F$ & $P$ value \\
\hline \multicolumn{6}{|l|}{ Detroit } \\
\hline Race & 309.3567 & 1 & 309.3567 & 16.4403 & $<0.005$ \\
\hline Sex & 33.9648 & 1 & 33.9648 & 1.8050 & $>0.10$ \\
\hline Age & 226.4567 & 3 & 75.4856 & 4.0116 & $<0.01$ \\
\hline \multicolumn{6}{|l|}{ Between } \\
\hline children & $11,817.0547$ & 628 & 18.8170 & $\ldots$ & $\ldots$ \\
\hline \multicolumn{6}{|l|}{ Columbia } \\
\hline Race & 22.0636 & 1 & 22.0636 & 1.1818 & $>0.10$ \\
\hline Sex & 5.6483 & 1 & 5.6483 & 0.3025 & $>0.10$ \\
\hline Age & 80.8411 & 3 & 26.9470 & 1.4434 & $>0.10$ \\
\hline \multicolumn{6}{|l|}{ Between } \\
\hline children & $5,420.7109$ & 826 & 18.6691 & & \\
\hline
\end{tabular}

were much less than expected, but consistent and significant.

Little difference also was found between caries experiences of northern and southern students. Although statistically significant, results from such a large sample used in the analysis of variance are not unusual findings. The sample, considered as a whole, was large enough to have minimized the probability of beta error. Nevertheless, expected differences in caries experience between whites and blacks in South Carolina were not found. Caries experience for both groups was similar. Results of investigation suggest that there is no strong genetic immunity to caries for young blacks. Animal studies ${ }^{10,11}$ demonstrated that changes in environmental factors such as bacteria and diet have produced dental caries in strains of rats that were previously resistant to caries. In the population studied, the strong increase in caries experience of blacks ap-

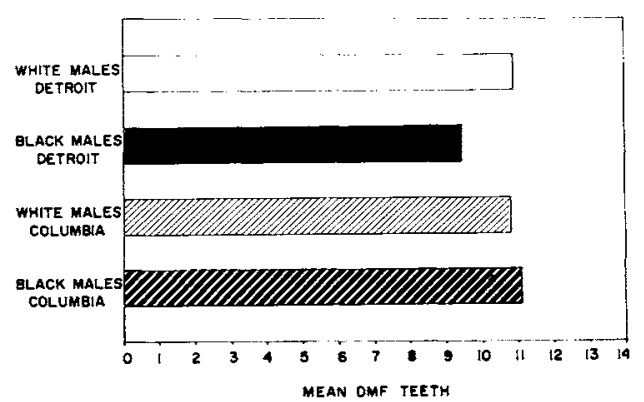

FIG 1.-Mean numbers of DMF teeth for white and black males, 14 to 17 years of age, in Detroit, Michigan, and Columbia, South Carolina, 1968.

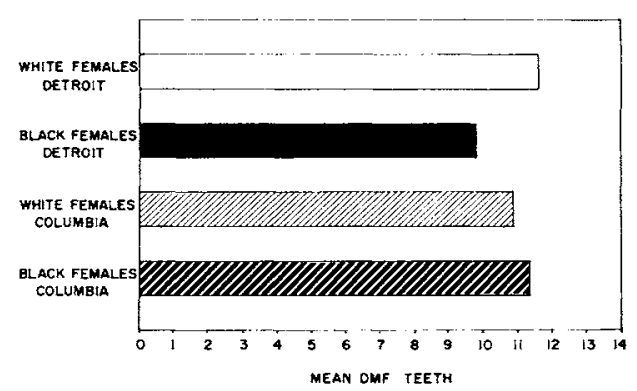

FIG 2.- Mean numbers of DMF teeth for white and black females, 14 to 17 years of age, in Detroit, Michigan, and Columbia, South Carolina, 1968.

parentiy has outweighed any genetic factor that might have been responsible for low caries experience in the past.

\section{Conclusions}

Racial differences in the prevalence and severity of caries experience did not exist among these groups of white and black students. Geographic differences did not exist in the prevalence and severity of caries experience between these residents of Detroit, Michigan, and Columbia, South Carolina. Southern white and black students have a similar caries experience, as do Northern white and black students.

\section{References}

1. KeLLY, J.E.; VAN KIRK, L.E.; and GarST, C.C.: Decayed, Missing, and Filled Teeth in Adults, United States-1960-1962, USPHS, National Center for Health Statistics, Series 11, No. 23, Washington: Government Printing Office, Feb 1967. 
2. Summers, C.J.; Bagramian, R.A.; and Russell, A.L.: Dental Caries Experience in Caucasian and Negro children living in Wayne County, Michigan, abstracted, IADR Program and Abstracts of Papers, No. 311, 1969.

3. Wells, J.E.; Carter, W.J.; Copeland, J.; and COE, G.H.: Oral Health Survey of 29,550 Kansas City, Missouri, Elementary School Children, $J$ Missouri Dent Assn 38:8-15, 1958.

4. Bellinger, W.R.: A Study of the Dental Caries Experience and the Fluoride Content of the Drinking Water of 1,472 White and 418 Negro Children in Kansas City, Kansas, $J$ Kansas Dent Assn 37:120-6, 1953.

5. Frenzel, W.W., and Triani, P.A.: Fluoridation in Richmond: a Ten-Year Evaluation, Virginia Dent $J$ 41:9-15, 1964.

6. Fulton, J.T.; Hughes, J.T.; and Mercer, C.V.: The Natural History of Dental Diseases, Chapel Hill: University of North Carolina, School of Public Health, 1965, pp 15, 43.

7. Miller, S.L.; and Chrietzberg, J.D.:
Caries Experience Among Children in Two Fluoridated Communities Where the Fluoride Concentration Was Adequately Maintained in Only One, Pub Health Den 22: $61-75,1962$.

8. Klein, H., and Palmer, C.E.: On the Epidemiology of Dental Caries, in KLEIN, H., ET AL: University of Pennsylvania Bicentennial Conference, Dental Caries, Philadelphia: University of Pennsylvania Press, 1941, pp 1-25.

9. Messner, C.T., ET AL: Dental Survey of School Children Ages 6-14 Years Made in 1933-34 in 26 States, USPHS, Public Health Bulletin No. 226, Washington: Government Printing Office, 1936, pp 28227.

10. Keyes, P.H.: The Infectious and Transmissible Nature of Experimental Dental Caries, Arch Oral Biol 1:304-20, 1960.

11. LARSON, R.H.: Genetic and Environmental Factors in Experimental Dental Caries, in KRESHOVER, S.J., and MCCluRE, F.J. (eds), Environmental Variables in Oral Disease, Washington: AAAS, 1966, pp 89102. 